\title{
Ethnic Differences in Risk Factors for Obesity among Adults in California, the United States
}

\author{
Liang Wang, ${ }^{1}$ Jodi Southerland, ${ }^{2}$ Kesheng Wang, ${ }^{1}$ Beth A. Bailey, ${ }^{3}$ Arsham Alamian, ${ }^{1}$ \\ Marc A. Stevens, ${ }^{1}$ and Youfa Wang ${ }^{4}$ \\ ${ }^{1}$ Department of Biostatistics and Epidemiology, College of Public Health, East Tennessee State University, Johnson City, TN, USA \\ ${ }^{2}$ Department of Community and Behavioral Health, College of Public Health, East Tennessee State University, Johnson City, TN, USA \\ ${ }^{3}$ Department of Family Medicine, Quillen College of Medicine, East Tennessee State University, Johnson City, TN, USA \\ ${ }^{4}$ Fisher Institute of Health and Well-Being, Systems-Oriented Global Childhood Obesity Intervention Program, \\ Department of Nutrition and Health Sciences, College of Health, Ball State University, Muncie, IN, USA
}

Correspondence should be addressed to Liang Wang; wang12@etsu.edu

Received 2 August 2016; Revised 1 February 2017; Accepted 12 February 2017; Published 2 March 2017

Academic Editor: Aron Weller

Copyright (C) 2017 Liang Wang et al. This is an open access article distributed under the Creative Commons Attribution License, which permits unrestricted use, distribution, and reproduction in any medium, provided the original work is properly cited.

Little attention has been given to differences in obesity risk factors by racial/ethnic groups. Using data from the 2011-2012 California Health Interview Survey, we examined differences in risk factors for obesity among Whites, Latinos, Asians, and African Americans among 42,935 adults (24.8\% obese). Estimates were weighted to ensure an unbiased representation of the Californian population. Multiple logistic and linear regression analyses were used to examine the differences in risk factors for obesity. Large ethnic disparities were found in obesity prevalence: Whites (22.0\%), Latinos (33.6\%), African Americans (36.1\%), and Asians (9.8\%). Differences in risk factors for obesity were also observed: Whites (gender, age, physical activity, smoking, arthritis, and diabetes medicine intake), Latinos (age, arthritis, and diabetes medicine intake), Asians (age, binge drinking, arthritis, and diabetes medicine intake), and African Americans (gender, physical activity, smoking, binge drinking, and diabetes medicine intake). Females were more likely to be obese among African Americans (odds ratio $(\mathrm{OR})=1.43,95 \%$ confidence interval $(\mathrm{CI})=1.05-1.94)$, but less likely among Whites $(\mathrm{OR}=0.80,95 \% \mathrm{CI}=0.74-0.87)$. Race/ethnicity should be considered in developing obesity prevention strategies.

\section{Introduction}

The obesity epidemic in the United States (U.S.) has become a public health crisis [1-6]. Data from the 2011-2012 U.S. national survey showed that the prevalence of adult obesity was $34.9 \%$ and varied by ethnicity (e.g., $10.8 \%$ for nonHispanic Asians, 32.6\% for non-Hispanic Whites, $42.5 \%$ for Hispanics, and $47.8 \%$ for non-Hispanic Blacks) [3]. With the exception of Asians, the prevalence of grade 2 obesity (body mass index $[\mathrm{BMI}] \geq 35)$ and grade 3 obesity $(\mathrm{BMI} \geq 40)$ was significantly higher among racial/ethnic minorities than in Whites, particularly among females [3]. Numerous crosssectional and longitudinal studies have identified similar trends [4-6]. National health objectives call for the elimination of health disparities and achievement of health equity [7]. Racial/ethnic minorities currently comprise $36.3 \%$ of the U.S. population and are expected to increase to more than
$50 \%$ of the total population by $2050[8,9]$. Disproportionate increases in the prevalence of obesity have led to persistent disparities, particularly among non-Whites [6].

Among adults in California, 35.0\% were overweight and $24.7 \%$ were obese in 2014 [10]. An earlier report showed racial/ethnic differences in average BMI in Californian adults for both sexes, with larger difference in females [11]. Limited studies have reported the recent prevalence of obesity among Californian adults by demographics. To date, most research in adult obesity trends has focused on differences in the prevalence of obesity by individual, socioeconomic, or neighborhood characteristics [12-15], with less attention given to differences in obesity risk factors by racial/ethnic groups.

This study aimed to examine obesity-related risk factors among four major ethnic groups (Whites, Latinos, Asians, and African Americans [AAs]) in California using data from 
the 2011-2012 California Health Interview Survey (CHIS). This information can be used to develop targeted obesity prevention interventions and help eliminate health disparities over time.

\section{Methods}

2.1. Data and Sample Selection. The CHIS is a collaborative study of the University of California, Los Angeles Center for Health Policy Research, the California Department of Health Services, and the Public Health Institute. As one of the largest health surveys in the nation, this population-based randomdigit dial telephone survey has been conducted every other year in California since 2001. The survey examines public health and healthcare access issues in the state. The 20112012 CHIS is the sixth data collection cycle for this survey since 2001. Among the randomly selected households, one adult who was 18 years or older was then randomly selected as the respondent. Details about the sampling design and methodology can be found elsewhere [16]. Procedures for data collection and analysis were approved by the Institutional Review Boards (IRBs) at the participant universities and agencies. The current study was approved by the IRB of the authors' university.

Due to small sample sizes for Pacific Islander $(n=73$, $0.17 \%)$, American Indian/Alaskan native $(n=636,1.48 \%)$, and other single/multiple racial groups ( $n=3,065 ; 7.14 \%)$, we combined them as "other." In the current study, a total of 42,935 adults were included in the analysis, including 26,376 (61.43\%) Whites, 6,453 (15.03\%) Latinos, 4,253 (9.91\%) Asians, 2,079 (4.84\%) AAs, and 3,774 (8.79\%) adults classified as "other."

\section{Measures}

3.1. Dependent Variable. Obesity was defined as a BMI of $30 \mathrm{~kg} / \mathrm{m}^{2}$ or more. BMI was calculated from self-reported height and weight.

3.2. Independent Variables. Respondents' race was categorized as White, Latino, Asian, AA, and other. Gender was dichotomized to male or female. Respondents' age at the time of the interview was categorized into three levels: 1844 years, 45-64 years, and 65 years or older. In addition, respondents were asked about employment status, for example, (i) "full-time employment (>21 hours/week)," (ii) "parttime employment (0-20 hours/week)," (iii) “employed and not at work," (iv) "unemployed and looking for work," and (v) "unemployed and not looking for work." In the present study, employment status was dichotomized to yes (i-iii) or no (iv, v). For physical activity, respondents answered "yes" or "no" to the question "Have you walked at least 10 minutes for leisure in the past 7 days?" Respondents were also asked about smoking habits. Responses included "currently smokes," "quit smoking," and "never smoked regularly." In the present study, smoking status was defined as "never," "current," or "past." Binge drinking for males was defined as those who had five or more drinks on at least one occasion in the past month while female binge drinkers were those that had four or more drinks. Frequent binge drinking was defined as engaging in binge drinking daily or weekly, monthly, or more than monthly but less than weekly in the past year. Infrequent binge drinking was defined as engaging in binge drinking once in the past year, more than once but less than monthly in the past year. For arthritis status, respondents answered "yes" or "no" to the question "Has a doctor ever told have arthritis, gout, or lupus?" With regard to diabetes medicine intake, respondents answered "yes" or "no" to the question "Are you currently taking diabetes pills to lower blood sugar?" Furthermore, serious psychological distress (SPD) was determined using the Kessler psychological distress scale (K6) [17], which comprises six questions asking how often during the past 30 days a person felt "so sad that nothing could cheer them up," "nervous," "restless," "hopeless," "worthless," or that "everything was an effort." SPD is a nonspecific measure of psychological distress that has been psychometrically validated and can detect community DSM-IV cases from noncases. Responses are scored from 0 (none of time) to 4 (all the time) and summed to produce a total score. A score of 13 or above was defined as having SPD [17].

3.3. Statistical Analysis. Estimates from the CHIS sample were weighted to ensure an unbiased representation of the Californian population. SAS PROC SURVEYLOGISTIC procedure was used to estimate odds ratios (ORs) and 95\% confidence intervals (CIs) for the association between independent variables and the prevalence of obesity. SAS PROC SURVEYREG procedure was used to estimate regression coefficients and standard errors for the association between independent variables and BMI. Multiple logistic and linear regression analyses were used to examine the association between all the independent variables and obesity and BMI. Race was found to have significant interactions with gender, age, physical activity, binge drinking, and diabetes medicine intake (all $P$-interaction $<0.05$ ). Multiple logistic and linear regression analyses were then used to examine the differences in risk factors for obesity and BMI in Whites, Latinos, Asians, and AAs, respectively. All analyses were performed using SAS statistical software, version 9.2 (SAS Institute, Cary, NC, USA).

\section{Results}

Overall, the prevalence of obesity was $24.8 \%$ among Californian adults. Compared to Whites (22.0\%), Latinos (33.6\%) and AAs (36.1\%) had a higher prevalence of obesity while Asians had a lower prevalence (9.8\%). Individuals who were male, between the ages of 45-64 years, and unemployed had a higher prevalence of obesity than their counterparts. Other risk factors for obesity included lack of physical activity, past smoking, arthritis, use of diabetes medicine, and presence of SPD (Table 1).

Figure 1 shows the prevalence of obesity by ethnicity and gender. Asian women had the lowest prevalence of obesity, whereas AA women had the highest. Gender disparity in obesity prevalence appeared to be largest in AAs. Among men, ethnic disparities in obesity prevalence were largest 
TABLE 1: The prevalence (\%) of obesity according to characteristics of participants, the 2011-12 CHIS $(n=42,935)$.

\begin{tabular}{|c|c|c|c|c|}
\hline Characteristics & Sample size & Prevalence (\%) & $95 \% \mathrm{CI}$ & $P$ value $^{*}$ \\
\hline Overall & 42,935 & 24.8 & $24.2-25.4$ & \\
\hline \multicolumn{5}{|l|}{ Race } \\
\hline White & 26,376 & 22.0 & $21.3-22.7$ & \multirow{5}{*}{$<0.0001$} \\
\hline Latino & 6,453 & 33.6 & $31.8-35.4$ & \\
\hline Asian & 4,253 & 9.8 & $8.2-11.4$ & \\
\hline African American & 2,079 & 36.1 & $32.8-39.4$ & \\
\hline Other & 3,774 & 29.9 & $27.5-32.4$ & \\
\hline \multicolumn{5}{|l|}{ Gender } \\
\hline Male & 17,848 & 25.8 & $24.9-26.6$ & \multirow{2}{*}{$<0.0001$} \\
\hline Female & 25,087 & 23.9 & $23.1-24.7$ & \\
\hline \multicolumn{5}{|l|}{ Age in years } \\
\hline $18-44$ & 12,010 & 21.8 & $20.8-22.8$ & \multirow{3}{*}{$<0.0001$} \\
\hline $45-64$ & 16,810 & 30.1 & $28.9-31.3$ & \\
\hline $65+$ & 14,115 & 23.1 & $22.1-24.1$ & \\
\hline \multicolumn{5}{|l|}{ Employment } \\
\hline No & 21,424 & 26.3 & $25.2-27.4$ & \multirow{2}{*}{0.0005} \\
\hline Yes & 21,511 & 23.9 & $23.0-24.7$ & \\
\hline \multicolumn{5}{|l|}{ Physical activity } \\
\hline No & 15,823 & 28.0 & $26.9-29.2$ & \multirow{2}{*}{$<0.0001$} \\
\hline Yes & 26,763 & 23.0 & $22.1-23.8$ & \\
\hline \multicolumn{5}{|l|}{ Smoking status } \\
\hline Never & 25,405 & 23.3 & $22.5-24.2$ & \multirow{3}{*}{$<0.0001$} \\
\hline Current & 4,977 & 25.2 & $23.3-27.1$ & \\
\hline Past & 12,553 & 28.6 & $27.3-29.8$ & \\
\hline \multicolumn{5}{|l|}{ Binge drinking } \\
\hline Never & 32,863 & 24.9 & $24.2-25.7$ & \multirow{3}{*}{0.378} \\
\hline Infrequent & 5,948 & 25.2 & $23.5-26.9$ & \\
\hline Frequent & 4,124 & 23.4 & $21.1-25.7$ & \\
\hline \multicolumn{5}{|l|}{ Arthritis } \\
\hline No & 29,760 & 22.5 & $21.8-23.2$ & \multirow{2}{*}{$<0.0001$} \\
\hline Yes & 13,175 & 33.9 & $32.5-35.3$ & \\
\hline \multicolumn{5}{|c|}{ Diabetes medicine intake } \\
\hline No & 38,234 & 22.7 & $22.1-23.3$ & \multirow{2}{*}{$<0.0001$} \\
\hline Yes & 3,396 & 48.6 & $45.8-51.5$ & \\
\hline \multicolumn{5}{|c|}{ Serious psychological distress } \\
\hline No & 41,199 & 24.4 & $23.9-25.0$ & \multirow{2}{*}{$<0.0001$} \\
\hline Yes & 1,515 & 35.2 & $30.7-39.7$ & \\
\hline
\end{tabular}

CHIS, California Health Interview Survey; CI, confidence interval.

${ }^{*} P$ value is calculated from $\chi^{2}$ test.

Notes. Sampling weights were used in analysis. Results in bold indicate statistically significant findings.

between Latino and Asians. Among women, disparities were largest between AAs and Asians. Overall, these differences were greater among women than among men.

Multivariate regression analyses of the associations between all potential risk factors and obesity/BMI are shown in Table 2. Multiple logistic regression analyses showed that compared to Whites, Latinos (OR $=1.94,95 \% \mathrm{CI}=1.76-2.15)$ and $\mathrm{AAs}(\mathrm{OR}=1.96,95 \% \mathrm{CI}=1.66-2.31)$ had an increased likelihood of being obese while Asians (OR $=0.41,95 \% \mathrm{CI}$ $=0.34-0.50)$ had a lower likelihood of being obese. Other risk factors for obesity included being male, 45-64 years of age, unemployment, lack of physical activity, past smoking, arthritis, and diabetes medicine intake (all $P<0.001$ ). Multiple linear regression analyses showed similar results for risk factors of BMI.

Table 3 shows the risk factors associated with obesity for each ethnic group after adjusting for covariates. Multiple logistic regression analyses showed that six risk factors (gender, age, physical activity, smoking, arthritis, and diabetes medicine intake) in Whites, three risk factors (age, arthritis, and diabetes medicine intake) in Latinos, four risk factors (age, binge drinking, arthritis, and diabetes medicine intake) 


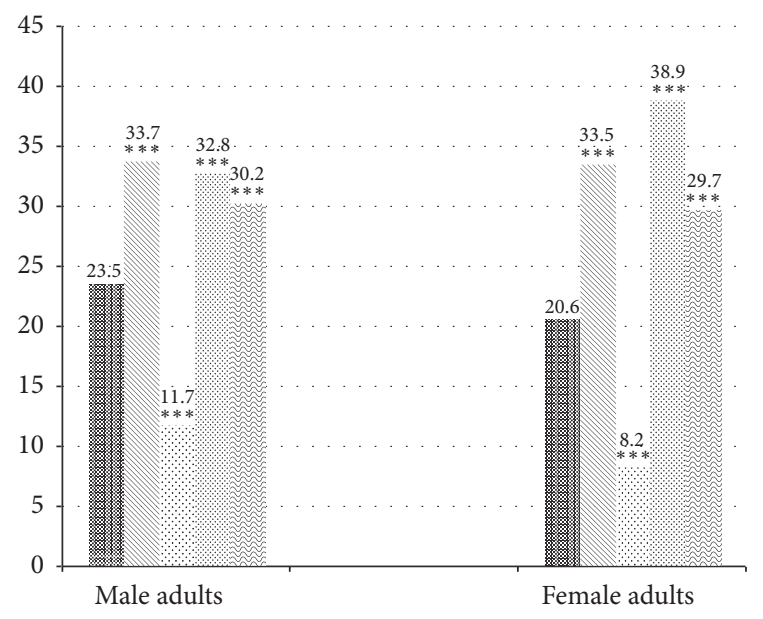

(\%)

\begin{tabular}{|c|c|}
\hline White & African American \\
\hline $\mathbb{N}$ Latino & 慈 Other \\
\hline
\end{tabular}

FIgURE 1: The prevalence (\%) of obesity of adults in California in the United States, 2011-2012, by ethnicity and gender. ${ }^{* * *} P<0.001$ versus Whites. Notes. $P<0.001$ for all ethnic groups versus Asians for both sexes. Not statistically significant (NS) for Latinos versus AAs, NS for the others versus AAs among men; $P<0.01$ for Latinos versus $A A s$ and $P<0.001$ for the others versus $A A s$ among women. NS for Latinos versus the others among men; $P<0.01$ for Latinos versus the others among women.

in Asians, and five risk factors (gender, physical activity, smoking, binge drinking, and diabetes medicine intake) in AAs were associated with obesity, respectively.

The estimated ORs varied markedly across these ethnic groups. Females were more likely to be obese for AAs $(\mathrm{OR}=$ $1.43,95 \%$ CI $=1.05-1.94)$, but less likely to be obese for Whites $(\mathrm{OR}=0.80,95 \% \mathrm{CI}=0.74-0.87)$; gender was not associated with obesity among Latinos and Asians. Whites and Asians who took diabetes medicine were more likely than Latinos and AAs to be obese (OR (95\% CI): 3.74 (3.14-4.45) and 3.25 (2.14-4.96) versus $2.30(1.79-2.95)$ and 2.24 (1.413.57)). The magnitude of differences in the association of risk factors with obesity also varied by ethnic group. The largest difference of OR was only 0.02 for the association of physical activity with obesity between Whites and AAs but was 1.17 for the association of arthritis with obesity between Asians and Whites.

Table 4 shows risk factors of BMI in different ethnic groups using multiple linear regression. Risk factors of BMI were the same as that of obesity for Whites and Latinos but varied for Asians and AAs. Five risk factors (gender, age, binge drinking, arthritis, and diabetes medicine intake) in Asians and six risk factors (age, physical activity, smoking, binge drinking, arthritis, and diabetes medicine intake) in AAs were associated with BMI, respectively. Specially, being female was associated with lower BMI for Whites and Asians $(\beta=-1.20,-1.59$, respectively, both $P<0.0001)$ and was not associated with BMI for Latinos and AAs. Whites and AAs with diabetes medicine intake had higher BMI than
Latinos and Asians $(\beta=4.42$ and 3.40 versus 2.01 and 2.12, respectively, all $P<0.0001)$. The magnitude of differences in the association between BMI and risk factors also varied by ethnic group. The largest difference of $\beta$ was 0.39 for the association of gender with BMI between Whites and Asians but was 2.14 for the association of diabetes medicine intake with BMI between Whites and Latinos.

\section{Discussion}

This study sheds important light on ethnic differences in risk factors associated with obesity. This is one of the first studies to examine variation in risk factors for obesity prevalence across ethnic groups using a large representative sample in California, where large ethnic differences exist in obesity rates. We observed several key findings. First, we found considerable ethnic disparity in adult obesity prevalence: AAs (36.1\%), Latinos (33.6\%), Whites (22.0\%), and Asians (9.8\%). The prevalence in AAs was three times larger than that in Asians. The difference in females was even greater; for example, the prevalence in AAs was about 5 times that in Asians (38.9\% versus 8.2\%). A key strength of our study is that it had an adequate sample of Asians, while other national surveys, for example, National Health and Nutrition Examination Survey, do not include adequate numbers of Asians. It should be noted that several studies have recommended lowering the conventional BMI cutoff points for Asians by 2 to 3 points [18-20]. In 2000, the World Health Organization's (WHO) International Association for the Study of Obesity and the International Obesity Task Force published a report recommending that BMI cutoff of $\geq 23$ and $\geq 25$ for classifying overweight and obese for some Asian groups, respectively [20]. The WHO Expert Consultation have reviewed several publications on this issue and determined that the associations for health risk, BMI, and body fat percentage differ between European and Asian populations. The research shows risk for BMI of $22-25 \mathrm{~kg} / \mathrm{m}^{2}$ and high risk for $\geq 26 \mathrm{~kg} / \mathrm{m}^{2}$ for Asian populations [19]. Another study examined the relationship between BMI and mortality among Asians and showed that high BMI was significantly associated with increased risk of mortality among Asian Americans. The study also reported no significant increase in mortality for Asian Americans with a BMI between 20 and 25. The study is against lowering the cutoff points of overweight and obesity for Asians [21]. Given the apparent lack of consensus on use of lower obesity BMI cutoff points for Asians, we defined obesity as BMI $\geq 30$, which may be indicative of the lower obesity percentage for Asians but may not necessarily mean that they are at lower health risk related to weight.

Another key finding is the considerable ethnic variation in the risk factors for obesity.

Only three (age, arthritis, and diabetes medicine intake), four (age, binge drinking, arthritis, and diabetes medicine intake), and five (gender, physical activity, smoking, binge drinking, and diabetes medicine intake) of the nine factors we examined were associated with obesity in Latinos, Asians, and AAs, respectively, while six (gender, age, physical activity, smoking, arthritis, and diabetes medicine intake) of the 
TABLE 2: Risk factors for obesity and BMI in U.S. adults, the 2011-12 CHIS ( $n=42,935)$.

\begin{tabular}{|c|c|c|c|c|c|c|}
\hline \multirow{2}{*}{ Characteristics } & \multicolumn{3}{|c|}{ Obesity (based on logistic regression) } & \multicolumn{3}{|c|}{ BMI (based on linear regression) } \\
\hline & OR & $95 \% \mathrm{CI}$ & $P$ value & $\beta$ & SE & $P$ value \\
\hline \multicolumn{7}{|l|}{ Race } \\
\hline \multicolumn{7}{|l|}{ White (ref) } \\
\hline Latino & 1.94 & $1.76-2.15$ & $<0.0001$ & 2.25 & 0.14 & $<0.0001$ \\
\hline Asian & 0.41 & $0.34-0.50$ & $<0.0001$ & -1.82 & 0.14 & $<0.0001$ \\
\hline African American & 1.96 & $1.66-2.31$ & $<0.0001$ & 2.10 & 0.22 & $<0.0001$ \\
\hline Other & 1.51 & $1.34-1.71$ & $<0.0001$ & 1.46 & 0.17 & $<0.0001$ \\
\hline \multicolumn{7}{|l|}{ Gender } \\
\hline \multicolumn{7}{|l|}{ Male (ref) } \\
\hline Female & 0.91 & $0.85-0.98$ & 0.0107 & -0.74 & 0.08 & $<0.0001$ \\
\hline \multicolumn{7}{|l|}{ Age in years } \\
\hline \multicolumn{7}{|l|}{$18-44$ years $($ ref $)$} \\
\hline $45-64$ years & 1.32 & $1.20-1.45$ & $<0.0001$ & 1.09 & 0.13 & $<0.0001$ \\
\hline $65+$ & 0.73 & $0.66-0.82$ & $<0.0001$ & -0.44 & 0.13 & 0.001 \\
\hline \multicolumn{7}{|l|}{ Employment } \\
\hline \multicolumn{7}{|l|}{ No (ref) } \\
\hline Yes & 0.97 & $0.88-1.06$ & 0.494 & 0.01 & 0.11 & 0.932 \\
\hline \multicolumn{7}{|l|}{ Physical Activity } \\
\hline \multicolumn{7}{|l|}{ No (ref) } \\
\hline Yes & 0.82 & $0.75-0.89$ & $<0.0001$ & -0.71 & 0.11 & $<0.0001$ \\
\hline \multicolumn{7}{|l|}{ Smoking status } \\
\hline \multicolumn{7}{|l|}{ Never (ref) } \\
\hline Current & 1.00 & $0.87-1.14$ & 0.956 & -0.24 & 0.13 & 0.084 \\
\hline Past & 1.19 & $1.09-1.29$ & $<0.0001$ & 0.48 & 0.10 & $<0.0001$ \\
\hline \multicolumn{7}{|l|}{ Binge drinking } \\
\hline \multicolumn{7}{|l|}{ No (ref) } \\
\hline Infrequent & 1.05 & $0.94-1.17$ & 0.427 & 0.18 & 0.15 & 0.233 \\
\hline Frequent & 0.99 & $0.85-1.16$ & 0.906 & -0.03 & 0.16 & 0.850 \\
\hline \multicolumn{7}{|l|}{ Arthritis } \\
\hline \multicolumn{7}{|l|}{ No (ref) } \\
\hline Yes & 1.66 & $1.52-1.82$ & $<0.0001$ & 1.50 & 0.12 & $<0.0001$ \\
\hline \multicolumn{7}{|c|}{ Diabetes medicine intake } \\
\hline \multicolumn{7}{|l|}{ No (ref) } \\
\hline Yes & 2.89 & $2.54-3.29$ & $<0.0001$ & 3.19 & 0.15 & $<0.0001$ \\
\hline \multicolumn{7}{|c|}{ Serious psychological distress } \\
\hline \multicolumn{7}{|l|}{ No (ref) } \\
\hline Yes & 1.17 & $0.95-1.45$ & 0.137 & 0.41 & 0.32 & 0.207 \\
\hline
\end{tabular}

CHIS, California Health Interview Survey; OR, odds ratio; CI, confidence interval.

Notes. Sampling weights were used in analysis. Results in bold indicate to be statistically significant.

factors were associated with obesity in Whites. Further, although obesity prevalence was actually higher in AAs and Latinos, risk factors in the present study were more strongly associated with obesity in Whites. These disparate observations suggest that other underlying biological, sociocultural, and environmental mechanisms not accounted for in the present study may have contributed to the obesity prevalence in ethnic minorities. For example, the literature suggests that social context and cultural factors are possible explanations for obesity disparities [22, 23]. Other studies suggest that since the majority of health disparities in adulthood have their etiological origin in childhood [24], it is important to examine factors linked to an individual's childhood such as maternal socioeconomic position [23]. More recent findings suggest, however, that the effect of socioeconomic status on obesity may be diminishing due to the increasing rates of obesity across ethnic, geographic, and community factors $[25,26]$. It is important to note that employment status (used 


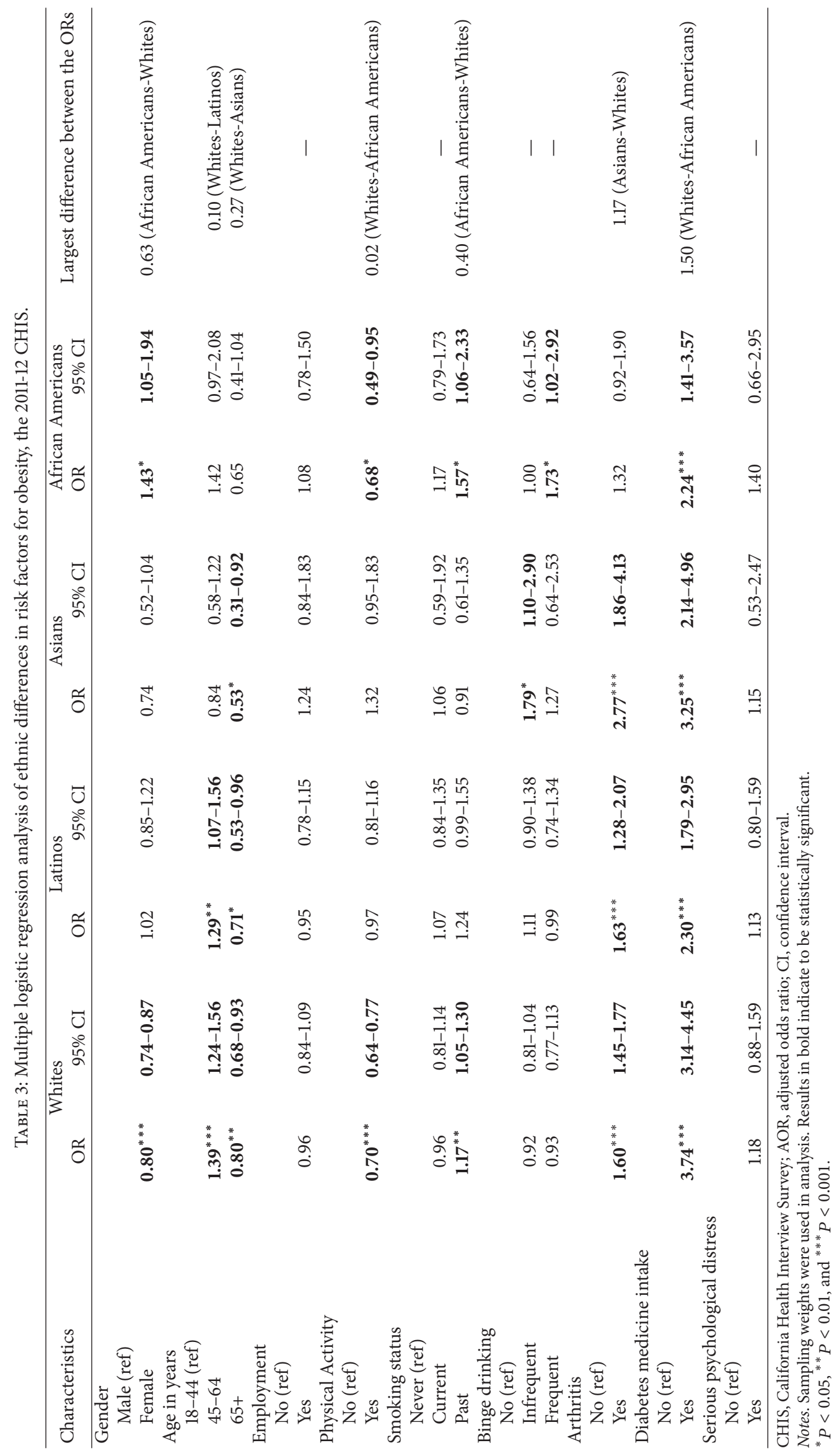


TABLE 4: Multiple linear regression analysis of ethnic differences in risk factors for body mass index (BMI).

\begin{tabular}{|c|c|c|c|c|c|}
\hline Characteristics & $\begin{array}{l}\text { Whites } \\
\beta \text { (SE) }\end{array}$ & $\begin{array}{l}\text { Latinos } \\
\beta(\mathrm{SE})\end{array}$ & $\begin{array}{l}\text { Asians } \\
\beta(\mathrm{SE})\end{array}$ & $\begin{array}{c}\text { African Americans } \\
\beta(\mathrm{SE})\end{array}$ & Largest difference between the $\beta$ 's \\
\hline \multicolumn{6}{|l|}{ Gender } \\
\hline \multicolumn{6}{|l|}{ Male (ref) } \\
\hline Female & $-1.20(0.09)^{* * *}$ & $0.15(0.27)$ & $-1.59(0.27)^{* * *}$ & $0.61(0.42)$ & 0.39 (Whites-Asians) \\
\hline \multicolumn{6}{|l|}{ Age in years } \\
\hline \multicolumn{6}{|l|}{$18-44$ (ref) } \\
\hline $45-64$ & $1.17(0.12)^{* * *}$ & $1.26(0.29)^{* * *}$ & $0.52(0.26)^{*}$ & $0.87(0.43)^{*}$ & 0.74 (Latinos-Asians) \\
\hline $65+$ & $-0.17(0.14)$ & $-0.87(0.42)^{*}$ & $0.29(0.45)$ & $-2.00(0.61)^{* *}$ & 1.13 (Latinos-African Americans) \\
\hline \multicolumn{6}{|l|}{ Employment } \\
\hline \multicolumn{6}{|l|}{ No (ref) } \\
\hline Yes & $0.11(0.12)$ & $-0.09(0.32)$ & $0.54(0.28)$ & $-2.29(0.44)$ & - \\
\hline \multicolumn{6}{|l|}{ Physical activity } \\
\hline \multicolumn{6}{|l|}{ No (ref) } \\
\hline Yes & $-0.97(0.09)^{* * *}$ & $-0.46(0.29)$ & $0.28(0.23)$ & $-1.40(0.40)^{* *}$ & 0.43 (Whites-African Americans) \\
\hline \multicolumn{6}{|l|}{ Smoking status } \\
\hline \multicolumn{6}{|l|}{ Never (ref) } \\
\hline Current & $-0.28(0.14)$ & $0.20(0.34)$ & $0.20(0.39)$ & $-0.78(0.50)$ & \\
\hline Past & $0.41(0.10)^{* * *}$ & $0.47(0.26)$ & $0.48(0.37)$ & $1.17(0.52)^{*}$ & 0.76 (African Americans-Whites) \\
\hline \multicolumn{6}{|l|}{ Binge drinking } \\
\hline \multicolumn{6}{|l|}{ No (ref) } \\
\hline Infrequent & $-0.02(0.14)$ & $0.10(0.31)$ & $1.27(0.41)^{* *}$ & $0.63(0.62)$ & - \\
\hline Frequent & $-0.20(0.17)$ & $0.001(0.38)$ & $0.62(0.51)$ & $1.82(0.75)^{*}$ & - \\
\hline \multicolumn{6}{|l|}{ Arthritis } \\
\hline \multicolumn{6}{|l|}{ No (ref) } \\
\hline Yes & $1.37(0.11)^{* * *}$ & $1.88(0.36)^{* * *}$ & $1.28(0.31)^{* * *}$ & $1.51(0.51)^{* *}$ & 0.60 (Latinos-Asians) \\
\hline \multicolumn{6}{|c|}{ Diabetes medicine intake } \\
\hline \multicolumn{6}{|l|}{ No (ref) } \\
\hline Yes & $4.42(0.22)^{* * *}$ & $2.01(0.33)^{* * *}$ & $2.12(0.44)^{* * *}$ & $3.40(0.71)^{* * *}$ & 2.41 (Whites-Latinos) \\
\hline \multicolumn{6}{|c|}{ Serious psychological distress } \\
\hline \multicolumn{6}{|l|}{ No (ref) } \\
\hline Yes & $0.30(0.31)$ & $0.13(0.47)$ & $-0.27(0.47)$ & $1.12(1.24)$ & - \\
\hline
\end{tabular}

SE, standard error.

Notes. Sampling weights were used in analysis. Results in bold indicate to be statistically significant.

${ }^{*} P<0.05,{ }^{* *} P<0.01$, and ${ }^{* * *} P<0.001$.

as a proxy for socioeconomic status) was not associated with obesity in any ethnic groups.

In this study, age, arthritis, and diabetes medicine intake were the most consistently identified risk factors for higher BMI and obesity. In some cases, age (e.g., among participants who were $65+$ years) played a protective role. However, middle age (i.e., 45-64 years) was associated with increasing BMI among all but one ethnic group. Arthritis was positively associated with BMI in all ethnic groups and positively associated with obesity in all ethnic groups except for AAs. Similarly, data from the 2003-2009 Behavioral Risk Factor Surveillance System reported that obesity prevalence in those with arthritis was 54\% higher than in nonarthritis patients [27]. Rheumatoid arthritis is an autoimmune disease that causes chronic inflammation affecting multiple synovial joints [28]. This form of arthritis can trigger metabolic alterations [29] that degrade lean tissue especially muscle mass [30]. The most common form of arthritis is osteoarthritis, traditionally affecting more older adults (>60 years) $[31,32]$. Combined with an inactive lifestyle, arthritis likely increases accumulation of body fat and body weight leading to reduced muscle mass [33].

On the other hand, research has shown that overweight/obese individuals are more likely to experience osteoarthritis in their knees, hips, and hands [34, 35], suggesting obesity is a risk factor for osteoarthritis, particularly knee osteoarthritis. Studies indicate that obesity increases the weight on a joint causing stress and the breakdown of cartilage that leads to knee and hip osteoarthritis [32, 36]. The cause of hand osteoarthritis has been linked to metabolic factors that are also associated with obesity such as adipocytokines [34]. More longitudinal studies are warranted to determine the potential pathways and interactions between arthritis and obesity.

Diabetes medicine intake was also positively associated with BMI and obesity in all ethnic groups. Adults with 
type 2 diabetes are more likely to report poorer healthrelated quality of life including limitations to daily activities thus increasing risk for obesity [37]. Given the increasing prevalence of arthritis (about 22\%) and type 2 diabetes (about 10\%) among U.S. adults [38, 39], clinicians should screen for chronic conditions to assess risk for obesity, particularly among adults between the ages of 45 and 64 years.

Lack of adequate physical activity is a key contributor of obesity in U.S. adults. Yet in the present study, we found that physical activity protected against obesity only among Whites and AAs. Interestingly, Whites are more likely to meet the federal guidelines for physical activity when compared to Asians and Hispanic/Latino populations (21.3\% versus $17.8 \%$ and $14.4 \%$, respectively). AAs are slightly less physically active than Asians but more active than Hispanics/Latinos [40]. Lifestyle behavior interventions focused on physical activity habits could result in weight loss in obese adults $[5,41]$ and reduce risk for obesity.

Our study has some limitations. First, the data are crosssectional and cannot test causality. Second, data on other potential obesity risk factors such as dietary habits, built environment, and neighborhood level characteristics [22, 42, 43 ] were not collected. Third, we did not include other known predictors of obesity such as comorbidities, acculturation, and nativity. Moreover, this study utilized self-reported data, which may suffer from report errors and bias. Nevertheless, previous research has shown that such self-reported data can be reliable and are widely used [44]. With regard to BMI, self-report measures are used ubiquitously in large, population-based studies despite the potential for systematic misreporting [45]. Large sample sizes are critical in the epidemiologic examination of various public health issues such as obesity. When using large sample sizes, however, there can be various opportunities for potential bias, including sampling error, measurement error, multiple comparisons errors, aggregation error, and errors associated with the systematic exclusion of information [46]. For this particular study, for example, some participants may have underestimated their BMI. Studies have documented error in selfreported BMI (e.g., over- or underestimates) [45]. While this is a potential limitation, a recent study provides promise. Racial/ethnic minorities (e.g., Blacks, Hispanics, and Native Americans) were found to more accurately report their BMI when compared to Whites [47].

Despite the limitations, the CHIS is the largest state health survey in the nation and one of the few to provide robust samples of many typically underrepresented racial and ethnic groups. Our study adds to the current literature by identifying ethnic variation in risk factors for obesity prevalence using a comprehensive state-level survey for adults. Variations by race underscore the influence of personal characteristics and contextual factors reported in previous studies [13, 14, 22]. There has been growing attention toward eliminating health disparities in the U.S. and toward improving the health of the population as a whole [7]. With the increasing diversity of America's population, it will be important for public health professionals and policy-makers to understand the determinants of obesity risk that are unique to ethnic groups when developing obesity prevention programming, a key target for eliminating health disparities.

\section{Conclusion}

Large disparities in the prevalence of obesity existed across ethnic groups in California. Risk factors for obesity also varied across ethnic groups. Understanding variations in risk factors is important for implementing effective obesity interventions in the increasingly diverse U.S. population. Public health practitioners and policy-makers cannot assume that obesity intervention programs and policies will impact ethnic groups uniformly. Therefore, public health and clinical interventions including communications on reducing obesity risk should be tailored to ethnic groups.

\section{Competing Interests}

The authors declare that they have no competing interests.

\section{Acknowledgments}

The authors thank the support of the 2011-2012 California Health Interview Survey, College of Public Health and Quillen College of Medicine of East Tennessee State University, and School of Public Health and Health Professions of University at Buffalo of State University of New York. Part of Dr. Youfa Wang's related effort was supported by research grants from the U.S. National Institutes of Health (NIH, 1R01HD064685-01A1, R01DK81335-01A1).

\section{References}

[1] Y. Wang, M. A. Beydoun, L. Liang, B. Caballero, and S. K. Kumanyika, "Will all Americans become overweight or obese? Estimating the progression and cost of the US obesity epidemic," Obesity, vol. 16, no. 10, pp. 2323-2330, 2008.

[2] Y. Wang and M. A. Beydoun, "The obesity epidemic in the United States-gender, age, socioeconomic, racial/ethnic, and geographic characteristics: a systematic review and metaregression analysis," Epidemiologic Reviews, vol. 29, no. 1, pp. 628, 2007.

[3] C. L. Ogden, M. D. Carroll, B. K. Kit, and K. M. Flegal, "Prevalence of childhood and adult obesity in the United States, 2011-2012," The Journal of the American Medical Association, vol. 311, no. 8, pp. 806-814, 2014.

[4] M. A. Beydoun and Y. Wang, "Pathways linking socioeconomic status to obesity through depression and lifestyle factors among young US adults," Journal of Affective Disorders, vol. 123, no. 1-3, pp. 52-63, 2010.

[5] K. M. Flegal, M. D. Carroll, C. L. Ogden, and L. R. Curtin, "Prevalence and trends in obesity among US adults, 1999-2008," The Journal of the American Medical Association, vol. 303, no. 3, pp. 235-241, 2010.

[6] C. X. Romero, T. E. Romero, J. C. Shlay, L. G. Ogden, and D. Dabelea, "Changing trends in the prevalence and disparities of obesity and other cardiovascular disease risk factors in three racial/ethnic groups of USA adults," Advances in Preventive Medicine, vol. 2012, Article ID 172423, 8 pages, 2012. 
[7] US Department of Health and Human Services, HealthyPeople.gov, Disparities; 2010, http://www.healthypeople.gov/2020/ about/disparitiesAbout.aspx.

[8] US Centers for Disease and Control and Prevention (CDC), Ethnic and Ethnic Minority Populations, 2012, https://www.cdc .gov/minorityhealth/.

[9] S. L. Colby and J. M. Ortman, "Projections of the Size and Composition of the U.S. Population: 2014 to 2060," Current Population Reports P25-1143, U.S. Census Bureau, Washington, DC, USA, 2014.

[10] Nutrition, Physical Activity and Obesity Data, Trends and Maps, U.S. Department of Health and Human Services, Centers for Disease Control and Prevention (CDC), National Center for Chronic Disease Prevention and Health Promotion, Division of Nutrition, Physical Activity and Obesity, Atlanta, Ga, USA, 2015, http://www.cdc.gov/nccdphp/DNPAO/index.html.

[11] H. Lee, "Obesity among California adults: ethnic and ethnic differences," Public Policy Institute of California, 2006, http:// www.ppic.org/content/pubs/report/R_906HLR.pdf.

[12] R. P. Lopez, "Neighborhood risk factors for obesity," Obesity, vol. 15, no. 8, pp. 2111-2119, 2007.

[13] J. Ludwig, L. Sanbonmatsu, L. Gennetian et al., "Neighborhoods, obesity, and diabetes-a randomized social experiment," The New England Journal of Medicine, vol. 365, no. 16, pp. 15091519, 2011.

[14] M. A. Papas, A. J. Alberg, R. Ewing, K. J. Helzlsouer, T. L. Gary, and A. C. Klassen, "The built environment and obesity," Epidemiologic Reviews, vol. 29, no. 1, pp. 129-143, 2007.

[15] C. E. Matthews, S. M. George, S. C. Moore et al., "Amount of time spent in sedentary behaviors and cause-specific mortality in US adults," American Journal of Clinical Nutrition, vol. 95, no. 2, pp. 437-445, 2012.

[16] California Health Interview Survey 2011-2012, Adult Public Data File 2011, UCLA Center for Health Policy Research, Los Angeles, Calif, USA, 2014, http://healthpolicy.ucla.edu/chis/design/ Documents/chis2011-2012_method-1_2014-06-09.pdf.

[17] R. C. Kessler, G. Andrews, L. J. Colpe et al., "Short screening scales to monitor population prevalences and trends in nonspecific psychological distress," Psychological Medicine, vol. 32, no. 6, pp. 959-976, 2002.

[18] W. C. Hsu, M. R. G. Araneta, A. M. Kanaya, J. L. Chiang, and W. Fujimoto, "BMI cut points to identify at-risk asian americans for type 2 diabetes screening," Diabetes Care, vol. 38, no. 1, pp. 150-158, 2015.

[19] WHO expert consultation, "Appropriate body-mass index for Asian populations and its implications for policy and intervention strategies," The Lancet, vol. 363, no. 9403, pp. 157-163, 2004.

[20] WHO, "The Asia-Pacific perspective: redefining obesity and its treatment," 2000, http://www.wpro.who.int/nutrition/documents/docs/Redefiningobesity.pdf.

[21] Y. Park, S. Wang, C. M. Kitahara et al., "Body mass index and risk of death in Asian Americans," American Journal of Public Health, vol. 104, no. 3, pp. 520-525, 2014.

[22] S. N. Bleich, R. J. Thorpe Jr., H. Sharif-Harris, R. Fesahazion, and T. A. LaVeist, "Social context explains race disparities in obesity among women," Journal of Epidemiology and Community Health, vol. 64, no. 5, pp. 465-469, 2010.

[23] L. J. Trotter, D. J. Bowen, and S. A. A. Beresford, "Testing for racial/ethnic differences in the association between childhood socioeconomic position and adult adiposity," American Journal of Public Health, vol. 100, no. 6, pp. 1088-1094, 2010.
[24] K. M. Ziol-Guest, G. J. Duncan, and A. Kalil, "Early childhood poverty and adult body mass index," American Journal of Public Health, vol. 99, no. 3, pp. 527-532, 2009.

[25] Q. Zhang and Y. Wang, "Trends in the association between obesity and socioeconomic status in U.S. adults: 1971 to 2000," Obesity Research, vol. 12, no. 10, pp. 1622-1632, 2004.

[26] Y. Wang and Q. Zhang, "Are American children and adolescents of low socioeconomic status at increased risk of obesity? Changes in the association between overweight and family income between 1971 and 2002," The American Journal of Clinical Nutrition, vol. 84, no. 4, pp. 707-716, 2006.

[27] Centers for Disease Control and Prevention (CDC), "Prevalence of obesity among adults with arthritis-United States, 2003-2009," Morbidity and Mortality Weekly Report, vol. 60, no. 16, pp. 509-513, 2011.

[28] K. Masuko, "Rheumatoid cachexia revisited: a metabolic comorbidity in rheumatoid arthritis," Frontiers in Nutrition, vol. 1, article 20, 2014.

[29] G. S. Metsios, A. Stavropoulos-Kalinoglou, V. F. Panoulas et al., "New resting energy expenditure prediction equations for patients with rheumatoid arthritis," Rheumatology, vol. 47, no. 4, pp. 500-506, 2008.

[30] R. Roubenoff, R. A. Roubenoff, J. G. Cannon et al., "Rheumatoid cachexia: cytokine-driven hypermetabolism accompanying reduced body cell mass in chronic inflammation," Journal of Clinical Investigation, vol. 93, no. 6, pp. 2379-2386, 1994.

[31] D. T. Felson, "Weight and osteoarthritis," The American Journal of Clinical Nutrition, vol. 63, supplement, pp. 430S-432S, 1996.

[32] M. R. Sowers and C. A. Karvonen-Gutierrez, "The evolving role of obesity in knee osteoarthritis," Current Opinion in Rheumatology, vol. 22, no. 5, pp. 533-537, 2010.

[33] A. Stavropoulos-Kalinoglou, G. S. Metsios, Y. Koutedakis et al., "Redefining overweight and obesity in rheumatoid arthritis patients," Annals of the Rheumatic Diseases, vol. 66, no. 10, pp. 1316-1321, 2007.

[34] N. Arden and M. C. Nevitt, "Osteoarthritis: epidemiology," Best Practice and Research: Clinical Rheumatology, vol. 20, no. 1, pp. 3-25, 2006.

[35] D. T. Felson, "An update on the pathogenesis and epidemiology of osteoarthritis," Radiologic Clinics of North America, vol. 42, no. 1, pp. 1-9, 2004.

[36] A. T. Toivanen, M. Heliövaara, O. Impivaara et al., "Obesity, physically demanding work and traumatic knee injury are major risk factors for knee osteoarthritis-a population-based study with a follow-up of 22 years," Rheumatology, vol. 49, no. 2, pp. 308-314, 2010.

[37] Centers for Disease Control and Prevention (CDC), National Center for Health Statistics, Division of Health Interview Statistics, data from the National Health Interview Survey. Statistical analysis by the CDC, National Center for Chronic Disease Prevention and Health Promotion, Division of Diabetes Translation, http://www.cdc.gov/diabetes/statistics/ mental/FigmentphyUS2008.htm.

[38] Centers for Disease Control and Prevention (CDC), "Prevalence of doctor-diagnosed arthritis and arthritis-attributable activity limitation-United States, 2007-2009," Morbidity and Mortality Weekly Report, vol. 59, pp. 1261-1265, 2010.

[39] Centers for Disease Control and Prevention (CDC), "National Diabetes Statistics Report," 2014, http://www.cdc.gov/diabetes/ pubs/statsreport14/national-diabetes-report-web.pdf. 
[40] V. L. Roger, A. S. Go, D. M. Lloyd-Jones et al., "Executive summary: heart disease and stroke statistics-2012 update: a report from the American Heart Association," Circulation, vol. 125, no. 1, pp. 188-197, 2012.

[41] B. H. Goodpaster, J. P. DeLany, A. D. Otto et al., "Effects of diet and physical activity interventions on weight loss and cardiometabolic risk factors in severely obese adults: a randomized trial," Journal of the American Medical Association, vol. 304, no. 16, pp. 1795-1802, 2010.

[42] P. A. Quatromoni, M. Pencina, M. R. Cobain, P. F. Jacques, and R. B. D’Agostino, "Dietary quality predicts adult weight gain: findings from the framingham offspring study," Obesity, vol. 14, no. 8, pp. 1383-1391, 2006.

[43] H. A. Beard, M. A. L. Ghatrif, R. Samper-Ternent, K. Gerst, and K. S. Markides, "Trends in diabetes prevalence and diabetesrelated complications in older Mexican Americans from 19931994 to 2004-2005," Diabetes Care, vol. 32, no. 12, pp. 2212-2217, 2009.

[44] D. L. Paulhus and S. Vazire, "The self-report method," in Handbook of Research Methods in Personality, R. W. Robins, R. C. Fraley, and R. F. Krueger, Eds., pp. 224-239, Guilford Press, New York, NY, USA, 2007.

[45] A. Hattori and R. Sturm, "The obesity epidemic and changes in self-report biases in BMI," Obesity, vol. 21, no. 4, pp. 856-860, 2013.

[46] R. M. Kaplan, D. A. Chambers, and R. E. Glasgow, "Big data and large sample size: a cautionary note on the potential for bias," Clinical and Translational Science, vol. 7, no. 4, pp. 342346, 2014.

[47] T. K. Richmond, I. Thurston, K. Sonneville, C. E. Milliren, C. E. Walls, and S. B. Austin, "Racial/ethnic differences in accuracy of body mass index reporting in a diverse cohort of young adults," International Journal of Obesity, vol. 39, no. 3, pp. 546-548, 2015. 


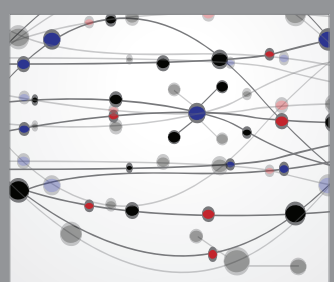

The Scientific World Journal


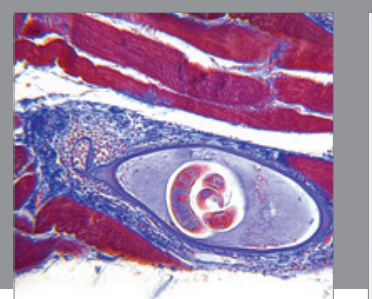

Gastroenterology Research and Practice
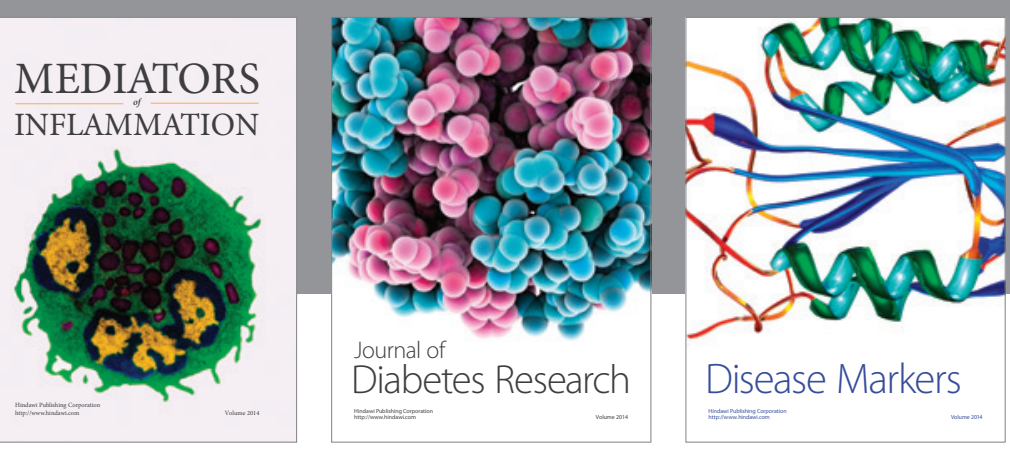

Disease Markers



\section{Hindawi}

Submit your manuscripts at

https://www.hindawi.com
